\title{
Analysis of the Coordination of International Policies Based on the Mundell-Fleming Model
}

\author{
Rui Cui \& Wen Fang \\ School of Economics and Management, Changchun University of Science and Technology \\ Changchun 130022, China \\ E-mail: cuirui_1980@163.com \\ Weiyi Wang \\ Party School of CPC Changchun Municipal Committee, Changchun 130000, China
}

The research is supported by the key project of "Study on the Interior and Exterior Double-Balance Coordination Development of Opening Economy" of the National Social Science Fund of China (No. GJA001). (Sponsoring information)

\begin{abstract}
IS-LM-BP model is the model of the interior and exterior double-imbalance state linking the interior economy with the international market in the opening economy. By applying the IS-LM-BP model in the economies of two economic entities, the international coordination effect of the opening economy macro policies are analyzed based on the view of the IS-LM-BP model, and the positive interaction of the macro policy international coordination between the China in the double imbalance with the interior stagnancy and the exterior surplus and the developed economic entity in the double imbalance with interior stagnancy and the exterior trade deficit in the global economic crisis is summarized and analyzed, and accordingly the short-term, middle-term, and long-term macro polices are suggested for China to realize the stable development of macro economy in the post-financial crisis.
\end{abstract}

Keywords: IS-LM-BP model, Fiscal policies, Monetary policies, Interior and exterior double-imbalance

\section{Introduction}

In 2007, the US Subprime Crisis burst out, and the macro economic structure of US got in another type double-imbalance of the macro-economy, i.e. the type of interior stagnancy and exterior trade deficit, from the double-imbalance with interior expansion and exterior trade deficit, and the global economic regression occurred. The world economy has generally gotten in the interior and exterior double-imbalance with interior stagnancy and exterior surplus or deficit. Comparing with the global Great Depression of 1930s, the theory and practice about the market economic macro policy adjustment has been quite matter in this global economic crisis. To deal with the economic depression of the native country, various countries have cooperated together and generally implemented the double-loose match including the financial policy and the monetary policy stimulating the economy almost in same period, which could not only produce the good conduction of emergence effect among various economic entities, but indicate the expansion of the macro economic adjustment in the global range and the enhancement of the international coordination, and be helpful to establish the global macro economy control mechanism. From 2010, the economies of various countries begun to regain subsequently, and the global economy has entered into a new flourishing cycle, especially China has entered into the growth stage with two digits, and for the problems such as how China makes the good conduction with big countries, and how China control the future direction of macro policy, it is necessary to summarize and analyze the good conduction of one countries macro economic policy to other countries by the Mundell-Fleming Model, which could provide not only theoretical and practical base of the future economic policy coordination, but also the references for the policy adjustment of China in the internationalization of RMB.

Mundell (1963) and Fleming (1962) expanded the IS-LM model to the analysis of the opening economy, and based on the IS-LM model, they added the BP curve which could reflect the exterior economic balance by the 
review of the flow of international capitals, and accordingly utilized the IS-LM-BP model to analyze the validity of the financial and monetary policies of one country in the opening economy. Therefore, the IS-LM-MP model is also called as the Mundell-Fleming model. In this article, the Mundell-Fleming model will be used to analyze and summarize the international coordination of the macro economy policy in the opening economy, and be applied in the research about China.

2. Model research premise and formula hypothesis of the opening economy macro-policy international coordination

Supposing that there are only two countries, the native country and the foreign country, and the spillover effect of the output of the native country to the foreign country is considered only, and to simplify the analysis, the feedback effect of the foreign country to the native country is not considered. The LM curves of the native country and the foreign country can be described as follows.

$$
\begin{aligned}
& r=\frac{k}{h} Y-\frac{1}{h}\left(\frac{M}{P}\right) \\
& r^{*}=\frac{k^{*}}{h^{*}} Y^{*}-\frac{1}{h^{*}}\left(\frac{M^{*}}{P^{*}}\right)
\end{aligned}
$$

Where, $\mathrm{r}$ denotes the interest rate, $\mathrm{Y}$ denotes the income, $\mathrm{M}$ denotes the quantity of money, $\mathrm{P}$ denotes the price, $\mathrm{k}$ and $\mathrm{h}$ are parameters respectively denoting the sensitivity of the monetary demand to the income and the sensitivity of the monetary demand to the interest rate, and the variables and the parameters of the foreign country are same, and they are denoted by *.

The IS curve of the native country is

$$
r=\frac{1}{d}\left(a+e+g+q-b t_{0}+b T r+n \frac{E P f}{P}\right)-\frac{1-b+g}{d} Y
$$

The IS curve of the foreign country is

$$
r^{*}=\frac{1}{d^{*}}\left(a^{*}+e^{*}+g^{*}+q^{*}-b^{*} t_{0}^{*}+b^{*} T r^{*}+n^{*} \frac{E P f}{P}+d^{*} Y\right)-\frac{1-b^{*}+g^{*}}{d^{*}} Y^{*}
$$

Where, $\alpha$ and $\beta$ respectively denote the autonomous consumption and the marginal consumption trend, $\mathrm{g}, \mathrm{t}_{0}$ and $\operatorname{Tr}$ respectively denote the government purchasing payout, taxation, and transfer payment, e denotes the autonomous investment, $\mathrm{d}$ denotes the sensitivity of the investment to the interest rate, $\mathrm{q}$ denotes the autonomous net export, $\mathrm{g}$ denotes the marginal import trend, $\mathrm{n}$ denotes the changing rate of the net export induced by the change of the practical exchange rate, and they are all parameters, E denotes the nominal exchange rate level in the direct pricing method, $\frac{E P_{f}}{P}$ denotes the actual exchange rate level, and the corresponding variables and parameters of the foreign country are denoted by *.

Because there are only two countries, and supposing that the obstacle of the capital flow doesn't exist, the interest rates of two countries are consistent when their foreign exchange markets are balanced, i.e.

$$
r=r^{*}
$$

\section{Model analysis of the opening economy macro-policy international coordination}

The Mundell-Fleming model is the platform to analyze the validity of the macro economic policy under different exchange rate systems. In the current international floating rate system, various countries have the selection spaces of the floating degrees to constitute the exchange rates, and whether the country adopts the floating-favored rate system or the pegged-favored rate system will produce completely different influences to the validity of the financial and monetary policies.

\subsection{International coordination analysis of the macro-economy policies in the floating rate system}

If the native country adopts the expanded financial policy, and the economy of the native economy is from A to B. In the product market, the economy of the native country expands and spills to the foreign country, and from the formula (1), IS* move outside, and the economy of the foreign economy is from $\mathrm{A}^{*}$ to $\mathrm{B}^{*}$. In the foreign exchange market, because the interest rate of the native country is higher than the interest rate of the foreign country, the BOP of the native country is surplus, and the value-increase of the native money and the depreciation of the foreign money would further depress the output of the native country and the increase the output of the foreign country, and the interest rate levels of various countries could be adjusted according to the movement of the IS curve, until the foreign exchange market achieves the balance on the new interest rate level. 
Finally, the economy of the native country and the economy of the foreign country will respectively achieve the state of $\mathrm{C}$ and the state of $\mathrm{C}^{*}$ (seen in Figure 1). The expansion of the financial policy of the native country will produce positive spillage effect to the economy of other country, and if all countries adopt the macro expansion financial policy, the positive interaction of the macro policy international coordination will be brought.

If the native country adopts the expanded financial policy, and the economy of the native economy is from A to B. In the product market, the economy of the native country expands and spills to the foreign country, and in the same way, the economy of the foreign country is from $\mathrm{A}^{*}$ to $\mathrm{B}^{*}$. In the foreign exchange market, because the interest rate of the native country is lower than the interest rate of the foreign country, the BOP deficit of the native country, the depreciation of the native money, and the value-increase of the foreign money will induce the further increase of the output of the native country, and the decrease of the output of the foreign country, and the interest rate level of all countries will be adjusted until the foreign exchange market achieves the balance on the new interest rate level. Finally, the economy of the native country and the economy of the foreign country will respectively achieve the state of $\mathrm{C}$ and the state of $\mathrm{C}^{*}$ (seen in Figure 2). The expansion of the financial policy of the native country will produce negative spillage effect to the economy of other country, and if all countries adopt the macro expansion financial policy to stimulate the export market and drive the economy by the large depreciation of money, the negative interaction of the macro policy international coordination will be brought.

\subsection{International coordination analysis of the macro-economy policies in the pegged rate system}

When the money of the native country and the money of the foreign country are pegged, if the native country adopts the expanded financial policy, i.e. the economy of the native country is from A to B. In the product market, the economy of the native country spills to the foreign country, and in the same way, the economy of the foreign country is from $\mathrm{A}^{*}$ to $\mathrm{B}^{*}$. In the foreign exchange market, because the interest rate of the native country is higher than the interest rate of the foreign country, the BOP surplus of the native country and the value of the native money increase to the boundary of the regulated extent, the central bank of the native country will enter into the market and intervene, and buy the foreign money and sell the native money, and the expansion of the native money supply will induce the return of the interest rate level and the decrease of the foreign money supply, and the output of the foreign country will rise continually because of the spillage effect of the native country, which will induce the rise of the foreign interest rate until the foreign exchange market achieves the balance on the new interest level. Finally, the economy of the native country and the economy of the foreign country will respectively achieve the state of $\mathrm{C}$ and the state of $\mathrm{C}^{*}$ (seen in Figure 3). In the pegged rate system, the international macro financial policy will bring the positive interaction of the economies of all countries.

If the native country adopts the expanded financial policy, i.e. the economy of the native country is from A to B. In the product market, the economy of the foreign country is from $\mathrm{A}^{*}$ to $\mathrm{B}^{*}$. Because the interest rate of the native country is lower than the interest rate of the foreign country, the BOP deficit of the native country and the value of the native money depreciate to the boundary of the regulated extent, the central bank of the native country will enter into the market and intervene, and buy the native money and sell the foreign money, and the contraction of the native money supply will induce the increase of the interest rate level and the decrease of the output, and the money supply of the foreign country will rise continually because of the spillage effect of the return of the output of the native country, which will induce the decrease of the foreign interest rate until the foreign exchange market achieves the balance on the new interest level. Finally, the economy of the native country and the economy of the foreign country will respectively achieve the state of $\mathrm{C}$ and the state of $\mathrm{C}^{*}$ (seen in Figure 4). In the pegged rate system, the international macro financial policy coordination will also bring the positive interaction.

\section{Analysis of the positive interaction of the macro policy international coordination between China and developed economic entity}

\subsection{Comparison of the IS-LM-BP curves between China and developed economic entity}

For the comparison of the IS curves between China and developed economic entities, according to the formula (3) and the formula (4), to comparing the slopes of the IS curves, the relative size of $d, \beta$, and $\gamma$ should be analyzed. Comparing with the perfected market economic entity such as US, the sensitivity of the Chinese investment demand to the interest rate is worse, because the size and the quantity of the private enterprises which are sensitive to the interest rate are small, and the quantity of the state owned enterprise is more, and the local governments would excessively intervene and dominate the local investments to drive the local economy, and the association between the investment change and the interest rate become smaller, and the private investment proportion in the investment demands of China is too high, which all will induce that the sensitivity of the investment demand to the interest rate is low in the existing market economy mode. As viewed from the time 
sequence, the marginal consumption tendency of China is always lower than 0.5 , below $2 / 3$ of the normal level, even the half level of the developed countries. As from the horizontal comparison, the marginal import tendency of China was in 0.14-0.284 (Wang Jinming \& Gao Tiemei, 2004), and the marginal import tendency was 0.159, and this value of Japan was 0.293 (Osada, 1999), that means the marginal import tendency of China is equivalent to US and Japan's. Therefore, considering from the factors influencing the slope of the IS curve, the slope of the IS curve of China is bigger and sharp.

For the comparison of the LM curves between China and developed economic entities, the depth and extent of the Chinese financial market is on the lower development level comparing with developed countries. In 2008, the surplus proportion of Chinese bonds only occupied 50\% of the GDP, and in 2006, there were 11.859 billion lots of global futures and options trading, and the quantity of the futures and options trading in China was only 449.5 million lots, and the quantity of the futures and options trading in US had exceeded 1 billion lots since 2003. In 2008, the account opening amount of the securities market of China was 138.87 million, one tenth of the population, but there are about 90 million families investing in the securities markets such as stock, national debt, and fund, one third of the population. It is obvious that the investable finance tools are very limited, and Chinese residents save most money in the bank to deal with the demands of transaction and reticence, and because a few quantity of money is invested in the gamble, so the monetary demand of China to the interest rate is not sensitive.

For the comparison of the BP curves between China and developed economic entity, because of the limitation of the capitals and the financial account, the BP curve of China is sharper than the LM curve, but almost all large developed economic entities have opened their capital accounts, and their BP curves are steadier. China is in the sate of international payment surplus at present, the left side of the BP curve. And the developed economic entities such as US are in the state of international payment deficit, the right side of the BP curve. Because the capital flow obstacles exist in the practical economic running, the foreign exchange markets of various countries will form the balanced state with different interest rates. Only considering the spillage effect of China to foreign countries, when the international payment curve expression of China changes nothing, the international payment curve expression of developed economic entities is

$$
B P^{*}=q^{*}-g^{*} Y^{*}+d^{*} Y+n^{*} \frac{E P_{f}}{P}-\left[s^{*}\left(r-r^{*}\right)\right]=0
$$

i.e.

$$
r^{*}=\frac{g^{*}}{s^{*}} Y^{*}+\left(r-\frac{n^{*}}{s^{*}} \frac{E P_{f}}{P}-\frac{q^{*}}{s^{*}}-\frac{d^{*} Y}{s^{*}}\right)
$$

\subsection{Analysis of the macro policy international coordination effects between China and developed economic entity}

As seen in Figure 5, the initial state of China is the crossing point A of IS1 and LM1, the left side of the BP curve, in the surplus state, and the initial state of the foreign country is the crossing point $\mathrm{A}^{*}$ of IS1* and LM1*, in the deficit state. China adopts the expanded financial policy, and IS1 moves to IS2, and A moves to B, and the output of China expands and spills to the foreign country, and IS1* expands to IS2*, and from A* to B*. The RMB in the surplus will increase in value, and the central bank will sell the native money continually, which makes the monetary supply of China expand and the output increase further, and the foreign money supply will reduce and the output will decrease. Though the interest rate of China is higher than the interest rate of foreign country, but because China implemented the capital control and limited the flow-in of capitals, the output increased and the international payment was improved, and finally it was in the double-balance state with balanced international payment and enhanced economic growth rate at the point of $\mathrm{C}$. Because the expansion of Chinese output drives the export demand of the foreign country, thought the interest rate of the foreign country is lower than the interest rate of China, but the drive effect of the output is larger. According to the formula (5), the BP1* moves to $\mathrm{BP} 2^{*}$, and at the point of $\mathrm{C}^{*}$, i.e. the crossing point of IS3*, $\mathrm{LM} 2^{*}$, and $\mathrm{BP} 2^{*}$, the foreign country will be at the sate of interior and exterior double-balance.

As seen in Figure 6, the initial states of two countries are described as above. China adopts the expanded monetary policy, and A moves to B, and the output of China expands and spills to the foreign country, and the state of the foreign country is from $A^{*}$ to $B^{*}$. At the same time, the RMB in the surplus begins to increase in value, and the central bank sells the native money continually, which makes that the monetary supply of China to be expanded and the output increases further, and the monetary supply of the foreign country reduce, and the output falls. The interest rate of China is lower than the interest rate of the foreign country, and the increase of output would improve the international payment of China and at the point of $\mathrm{C}$, China achieves the 
double-balance state with balanced international payment and enhanced economic growth rate. Because the output of China expands and drives the export demand of the foreign country and the interest rate of China reduces largely, according to the formula (7), BP1* moves to BP2*, i.e. the foreign country achieves the state of interior and exterior double-balance at the crossing point of IS2*, LM2*, and BP2*.

\section{Expectations of China macro-economy policies}

The influence of the subprime crisis of US on the economy of China begun to appear in 2008, and on the one hand, the interior economy was in the unbalanced state in the regression, and on the other hand, the international payment was still in the surplus, but the extent of the surplus reduced, and gradually went to the balanced state with a little surplus, but the improvement of the exterior unbalance costs the increasing interior unbalance, because the reduce of the trade surplus composing the exterior demands will bring the reduce of the total demand of the macro economy, so the government of China adopted a series of financial plans and measures to stimulate the economy, which could not only make China get rid of the shadow of the economic crisis as soon as possible, but also bring the positive spillage effect for other economic entities. To realize the coordination and healthy development of the interior and exterior double-balance of the Chinese economy and the positive interaction of the macro economic policy with other economic entities, and bring the global economy into another flourishing cycle, based on the IS-LM-BP model of China, in the short term, middle term, and long term, the macro policies of China should be mainly centralized in following adjustment domains according to different exchange rate systems.

First, in the short term, in the post-term of US financial crisis, if the economy is too hot or the economy depresses, China should deal with it by the economic growth mode adjusting the investment demand. Based on the fixed-favored exchange rate system of China, the financial policy is more effective, and the financial policy will be the dominant policy, i.e. the government should directly intervene to the investments in various domains, which could not only amplify the policy multiplier, but reduce the effect cycle. But the effect of the monetary policy changing the investment is very small, and it could only stabilize the price and prevent the large rise of the price in the economy stimulation process. In the fixed-favored exchange rate system, to further strengthen the effectiveness of the financial policy, the free flow of the international capitals must be quickened, and the free exchange of RMB should be realized, so in the short term, China should quicken the opening step of the capital item, and explore and constitute the security and supervision mechanism of the capital flow in the opening condition of the capital item.

Second, in the middle term, China should push the exchange rate and the domestic macro control from the mutual departure to mutual uniform and coordination, and push the economic growth from the dominance of the national investment and the exterior demand to the dominance of the civil investment and the public consumption. With the increase of the opening degree of China, the exchange rate policy will exert more and more important function in the economic control, and the freely floating rate of RMB will be the necessary choice in the future. In the freely floating rate system, the financial policy and the monetary policy will be effective completely. Since the rate adjustment of RMB was implemented in July of 2005, RMB has been always in the small-value-increasing tendency in the exchange rate target region. Since the financial crisis of US burst out and the export of China fell, the RMB begun to present unusual bilateral fluctuation since the July of 2008 , which provides a good chance to realize the floating rate for RMB in the future. To avoid the crowding out effect of the national investment to the civil capitals, the civil capitals and the foreign capitals should be allowed to enter into the monopolization industry, and the situation that various capitals compete should be formed. To stimulate the growth of the economy dominated by the domestic demand, Chinese residents' dominant income level should be enhanced (tax reduction), the income allocation gap should be reduced (perfecting the progressive taxation, supervising and limiting the multiple difference between the minimum income and the maximum income in the industry), and the social security system including education, medical treatment, unemployment, and endowment should be established and perfected. Taking the economic exterior demand crisis of China induced by the subprime crisis of US as the chance, China should make the domestic consumption demand be the main approach to drive the economic growth.

Third, in the long term, after the validity of the free exchange of capital item, the free floating of RMB, and the macro economic policy is enhanced, China should deepen the cooperation with East Asian countries in the monetary and financial domain, and act the dominant role in the regional monetary cooperation, and RMB should act as the basic currency in the East Asian regional monetary cooperation, and obtain bigger weight in the Asian monetary unit in the future. Further more, China should possibly use RMB to establish the East Asian regional base currency, and make the neighboring countries accept RMB in the spontaneous function of the market power, and make RMB become the main accounting and balance currency in the regional trade and 
investment. Here, the financial and monetary policy will not only act on the interior economy of China, but also influence other countries in East Asia, even the global economy, produce the spillage effect and accept the real feedback effect of other countries.

\section{References}

Betts C and Devereux M. (2000). Exchange Rate Dynamics in a Model of Pricing to Market. Journal of International Economics. No.50(1). P.215-244.

Hiroshi Osada. (1999). Intra-Regional Multiplier Effects through Trade Linkages in the APEC Area. [Online] Available: http://www.gsid.nagoya-u.ac.jp/project/apec/outcomes/paper99/27/Osada.pdf, 1999.

International Monetary Fund. (2009). World Economic Outlook, Crisis and Recovery. [Online] Available: http://www.imf.org/external/pubs/ft/weo/2009/01/index.htm

Jiang, Boke. (2002). Development Trend and Theoretical Frontier of the International Finance Theory. Finance by Research. No.9.

Liu, Yuhong. (2007). Empirical Analysis of the Validity of the Monetary Policy of China. Changchun: Doctor's Degree Thesis of Jilin University.

Maurice Obsfeld. (2001). International Macroeconomics: Beyond the Mundell-Fleming Mode. In NBER paper. No.8369.

Maurice Obstfeld and Rogoff Kenneth. (1995). Exchange Rate Dynamics Redux. Journal of Political Economy. No.103 (3). P.624-260.

Mundell. (1963). Capital Mobility and Stabilization Policy: under Fixed and Flexible Exchange Rates. Canadian Journal of Political and Economical Science. No.29(4). P.475-485.

Philip R. Lane. (2001). The New Open Economy Macroeconomics: a Survey. Journal of International Economics. August, No.54(2). P.235-266.

$\mathrm{Ru}, \mathrm{Xin}, \mathrm{Lu}, \mathrm{Xueyi}, \& \mathrm{Li}$, Peilin et al. (2008). Analysis and Forecasting of the Social Situation of China. Beijing: Social Sciences Academic Press.

Wang, Jinming \& Gao, Tiemei. (2004). Estimating the Multiplier of the Opening Economy of China by the Changeable Parameter Model. World Economy. No.4.

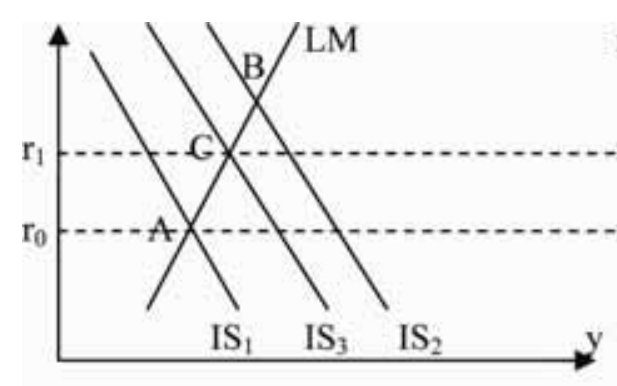

Home Economy

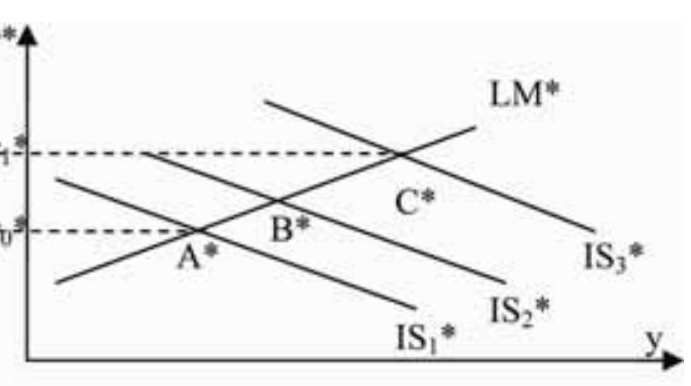

Foreign Economy

Figure 1. 


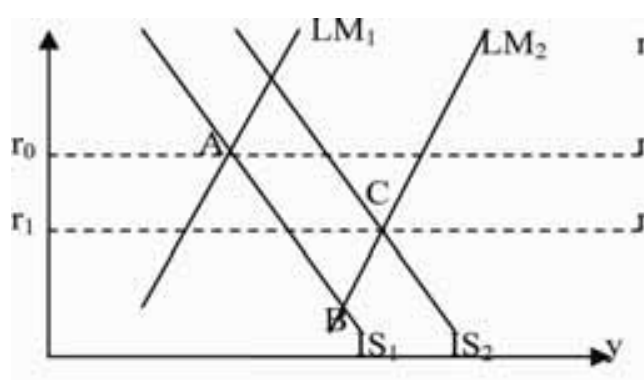

Home Economy

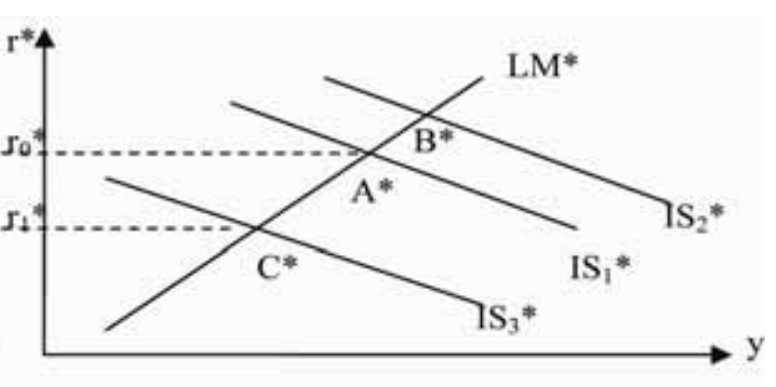

Foreign Economy

Figure 2.

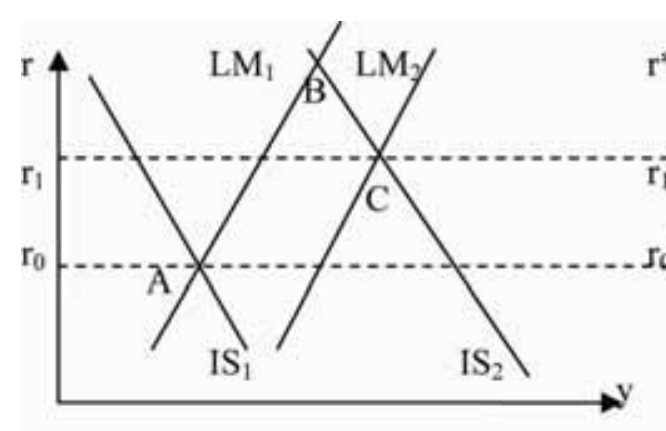

Home Economy

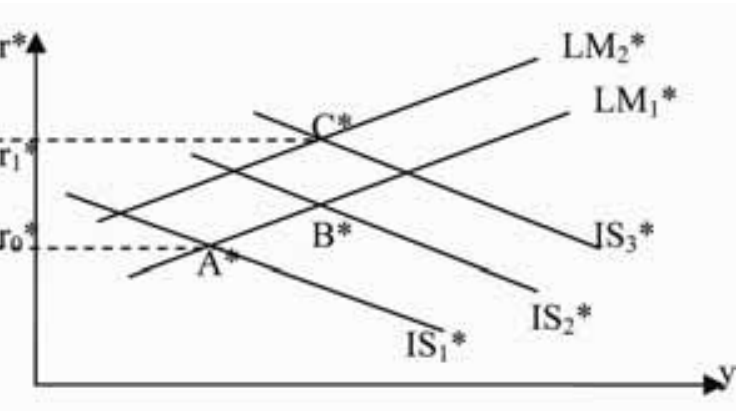

Foreign Economy

Figure 3.

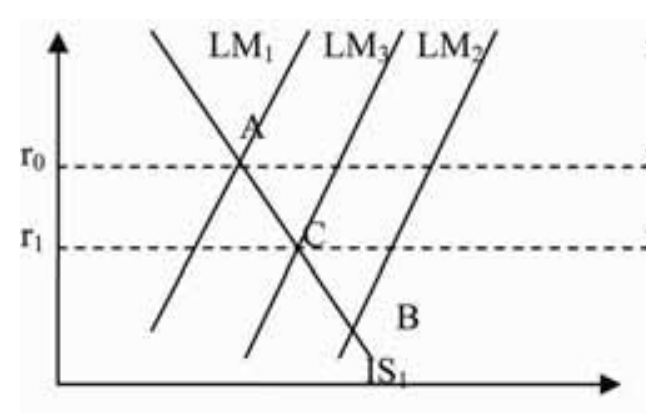

Home Economy

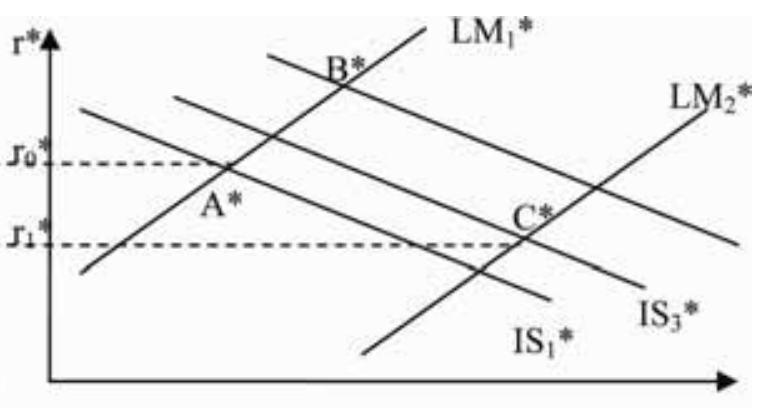

Foreign Economy

Figure 4. 


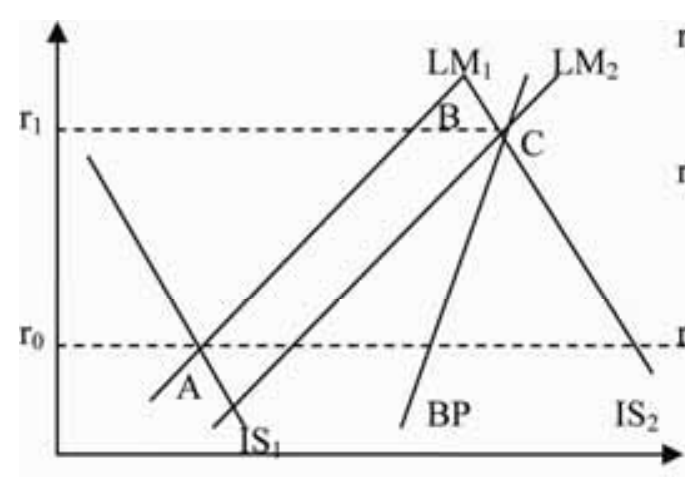

Home Economy

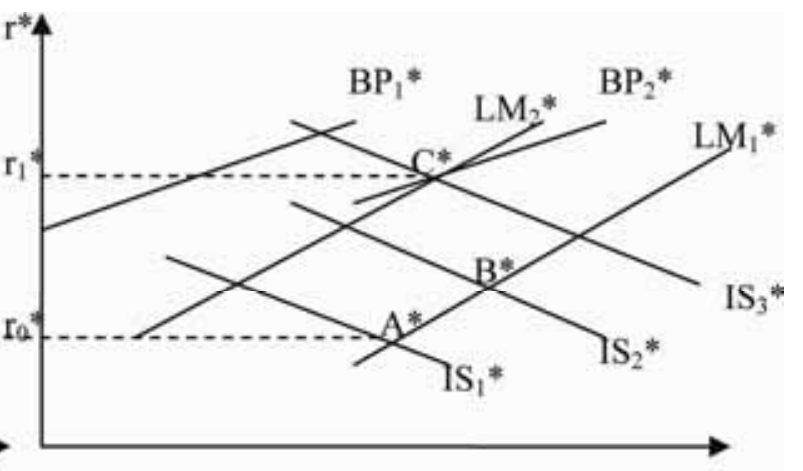

Foreign Economy

Figure 5.

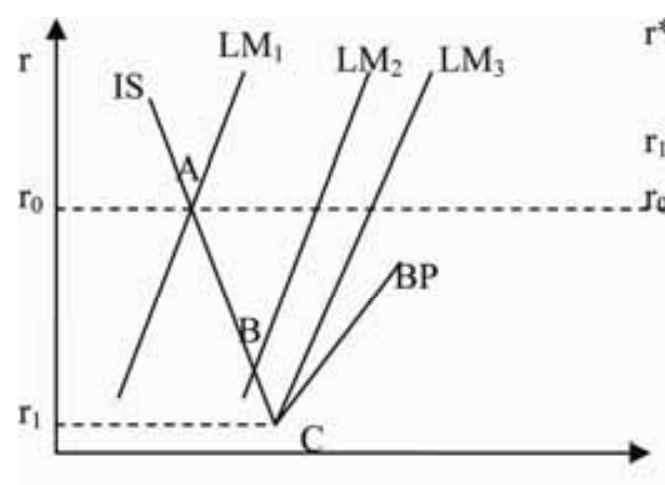

Home Economy

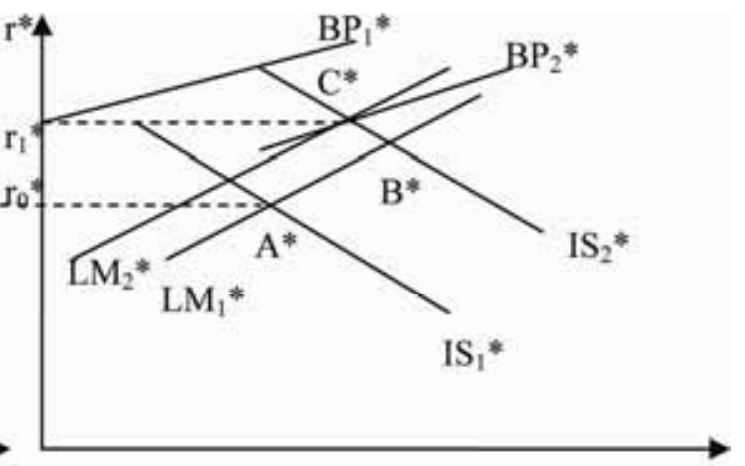

Foreign Economy

Figure 6. 